Brazilian Journal

of Chemical

ISSN 0104-6632

Engineering

Printed in Brazil

www.scielo.br/bjce

Vol. 35, No. 01, pp. 19 - 26, January - March, 2018

dx.doi.org/10.1590/0104-6632.20180351s20160452

\title{
HETEROTROPHIC CULTIVATION OF EUGLENA GRACILIS ON CHEMICALLY PRETREATED MEDIA
}

\author{
Mladen Pavlečić ${ }^{1}$, Dijana Crnić ${ }^{2}$, Ena Jurković ${ }^{3}$, \\ Mirela Ivančić Šantek ${ }^{1}$, Tonči Rezić ${ }^{1}$ and Božidar Šantek ${ }^{1 *}$ \\ ${ }^{1}$ Department of Biochemical Engineering, Faculty of Food Technology and Biotechnology, \\ University of Zagreb, Pierottijeva 6, 10000 Zagreb, Croatia \\ ${ }^{2}$ Ledo d.d., Marijana Čavića 1a, 10000 Zagreb, Croatia \\ ${ }^{3}$ Primevigilance Zagreb d.o.o., Oreškovićeva 20 A, 10000 Zagreb, Croatia
}

(Submitted: July 26, 2016; Revised: November 5, 2016; Accepted: December 8, 2016)

\begin{abstract}
In this research, the impact of chemical agents on the growth of Euglena gracilis and contaminants $(S$. cerevisiae and B. subtilis) in different cultivation media was studied. E. gracilis was cultivated on modified Hutner and complex medium in Erlenmeyer flasks and a stirred tank bioreactor. $\mathrm{H}_{2} \mathrm{O}_{2}$ and antimycin were used as suppressors of contaminant growth activities during algae cultivation. The use of antimycin as a chemical suppressor of contaminants is not recommendable because of its significant impact on the E. gracilis growth. At a $\mathrm{H}_{2} \mathrm{O}_{2}$ concentration of $5 \mathrm{mg} \mathrm{L}^{-1}$ contaminant growth activities were almost completely suppressed. In these conditions, E. gracilis is capable to grow, but a further increase of $\mathrm{H}_{2} \mathrm{O}_{2}$ concentration is related to significant reduction of algae growth. $\mathrm{H}_{2} \mathrm{O}_{2}$ as a suppressor of contaminants has great potential for industrial application, but its optimal concentration for a particular bioprocess has to be determined in order to obtain the maximal bioprocess efficiency.
\end{abstract}

Keywords: Euglena gracilis; heterotrophic cultivation; different cultivation media; $\mathrm{H}_{2} \mathrm{O}_{2}$; antimycin

\section{INTRODUCTION}

The microalgae Euglena gracilis is a well studied microorganism. It has great nutritional value because it contains valuable proteins in high concentrations (Murakami et al., 1998), polyunsaturated fatty acids, $\beta$-carotene, and vitamins C and E (Ogbona et al., 1998) among others. However, this microalgae is mostly recognized for paramylon ( $\beta$-1,3-glucan) production. This compound belongs to a group of biologically active polysaccharides, together with lentinan, fungal glucans, schizophyllan or pachyman, among others. Lentinan and schizophyllan are tumor suppressors and fungal glucans are well known immunostimulators (Watanabe et al.,
2013). Paramylon as a supplement has several human health benefits; it has anti-carcinogenic properties, it lowers blood cholesterol and its sulfonated derivatives can inhibit HIV virus activity (Koizumi et al., 1993). E. gracilis is capable of growing as a strict photoautotroph, a photo-heterotroph or a strict heterotroph utilizing organic carbon sources (Osafune et al., 1990). Under autotrophic conditions biomass yield is relatively low, so heterotrophic cultivation is more interesting for industrial application. E. gracilis is also capable of growing on several carbon sources and it has even been shown that it can grow on potato liquor and corn steep solids based media. The aim of these studies was to define simple and inexpensive complex media suitable for large scale heterotrophic cultivation of 
Euglena gracilis and paramylon production (Šantek et al., 2010; Šantek et al., 2012; Ivušić and Šantek, 2015). Medium type (composition) and medium optimization are highly important parts of any bioprocess as they can substantially reduce time and costs, as well as increase the bioprocess performance efficiency (Kennedy and Krouse, 1999). Various production modes (e.g., batch, fed-batch, continuous) or systems (e.g., shake flasks, bioreactors) can differ substantially regarding suitable medium composition due to their specific characteristics. The introduction of new mutants and strains in the bioprocess is frequently the reason for industrial optimization of medium composition (Kennedy and Krouse, 1999). Traditional or statistically designed approaches for media optimization can be used on numerous bioprocesses involving enzymes (Manivasagan et al., 2015), microorganisms (Li et al., 2014; Wang et al., 2014) or cell cultures (Almo and Love, 2014; Farrell et al., 2014). On the other hand, medium contaminations have to be avoided since their activity leads to lowering yields and other bioprocess efficiency parameters. Sterilization of equipment and medium, as well as aseptic manipulation techniques, are procedures usually used to avoid contamination during bioprocesses. In industrial bioprocesses these procedures are expensive, energyand time-consuming and therefore the use of chemicals could be an alternative. The selection of chemicals for this purpose is a demanding process due to the fact that chemicals with desirable selective toxicity and the exact concentration to be used must be previously determined. An excessive chemical concentration may modify the performance of the working microorganism or remain in the product, altering its properties (Oliveira et al., 2000). Chemical agents usually used for this purpose are: acids, basses, organic solvents, antibiotics or oxidants. An example of antibiotics application is the development of a sustainable procedure for controlling contaminant growth during the production of polyhydroxybutyric acid (PHB) by Alcaligenes eutrophus. In this research, erythromycin did not show a harmful effect on the bacterium growth. However, nitrofurantoin shows strong and streptomycin moderate harmful effects on A. eutrophus growth, respectively. Strongly harmful effect on PHB synthesis was only observed with nitrofurantoin (Oliveira et al., 2000). Furthermore, the successful application of vancomycin for the growth inhibition of Bacillus cereus in polyhydroxyalkanoate (PHA) production with Hydrogenophaga pseudoflava on whey containing media was also demonstrated (Koller et al., 2011).

The aim of this study was to investigate the effect of chemical agents $\left(\mathrm{H}_{2} \mathrm{O}_{2}\right.$ and antimycin) on the heterotrophic cultivation of E. gracilis in different experimental conditions. This study also shows how to suppress further growth of contaminants during the bioprocess if contamination happens after initial medium and bioreactor sterilization. In this research, heterotrophic cultivation of E. gracilis was performed in Erlenmeyer flasks and additionally verified in the stirred tank bioreactor.

\section{MATERIALS AND METHODS}

\section{Microorganisms and cultivation media}

Euglena gracilis strain Z (Klebs SAG 1224-5/25) was obtained from the Algensammlung Göttingen, Germany. The yeast $S$. cerevisiae and the bacterium B. subtilis were from the Culture collection of the Faculty of Food Technology and Biotechnology, University of Zagreb. Working microorganisms were maintained as follows: E. gracilis on modified Hutner medium (Hutner et al., 1966), S. cerevisiae on malt extract agar and B. subtilis on standard (containing beef, yeast, peptone and casein extract) agar, respectively. In this research, modified Hutner and complex medium [consisting of $20 \mathrm{~g} \mathrm{~L}^{-1}$ of glucose and $60 \mathrm{~g} \mathrm{~L}^{-1}$ of corn steep liquor (CSL)] were used for heterotrophic cultivation of $E$. gracilis. All media were sterilized at $121^{\circ} \mathrm{C}$ for $20 \mathrm{~min}$, then cooled down prior to inoculation and addition of chemical agents (with or without contaminants addition). Inocula of E. gracilis and contaminants (S. cerevisiae and B. subtilis) were prepared separately on the medium (modified Hutner or complex medium) that was used in further research. Inocula were propagated on the rotary shaker in $500 \mathrm{~mL}$ Erlenmeyer flasks with $200 \mathrm{~mL}$ medium at $28^{\circ} \mathrm{C}$ for 72 hours and rotation speed of $150 \mathrm{~min}^{-1}$. The cell number concentration in the E. gracilis inoculum was approx. $10^{7} \mathrm{CFU} / \mathrm{mL}$ and in $S$. cerevisiae and B. subtilis inocula in the range of 5 . $10^{7}-10^{8} \mathrm{CFU} / \mathrm{mL}$, respectively.

\section{Heterotrophic cultivation of $\boldsymbol{E}$. gracilis in Erlenmeyer flasks under different conditions}

Cultivations of E. gracilis were performed on modified Hutner medium in Erlenmeyer flasks $(200 \mathrm{~mL}$ of working volume in $500 \mathrm{~mL}$ flask; inoculum $10 \% \mathrm{v} / \mathrm{v}$ ) on a rotary shaker during five days at $28^{\circ} \mathrm{C}$ and rotation speed of $150 \mathrm{~min}^{-1} . \mathrm{H}_{2} \mathrm{O}_{2}$ (range of $1.5-15.0 \mathrm{mg} \mathrm{L}^{-1}$ ) and antimycin (range of $0.2-1.2 \mathrm{~g} \mathrm{~L}^{-1}$ ) were selected as suppressors of contaminants. Prior to inoculation, contaminants and chemicals addition, cultivation media were prepared and sterilized $\left(121^{\circ} \mathrm{C} / 20 \mathrm{~min}\right)$. The whole study consisted of different experimental set-ups that were characterized by different $E$. gracilis cultivation conditions. The same algae cultivation conditions were present inside a particular experimental setup (5 flasks).The control setup was the setup inoculated only with $E$. gracilis culture. Inoculum for separate $E$. gracilis co-cultivation with contaminants contains cell suspension of algae $(15 \mathrm{~mL})$ and contaminant $(5 \mathrm{~mL}$ ). Every 24 hours, one flask (from each experimental setup) was removed from the rotary shaker and used for analytical purposes. 
During the second part of this research E. gracilis was cultivated on complex $\left(20 \mathrm{~g} \mathrm{~L}^{-1}\right.$ of glucose and $60 \mathrm{~g} \mathrm{~L}^{-1}$ of CSL) medium in the selected experimental conditions according to the results obtained from research performed on the modified Hutner medium. In this part of research, E. gracilis was co-cultivated with contaminants and $\mathrm{H}_{2} \mathrm{O}_{2}$ addition $\left(5 \mathrm{mg} \mathrm{L}^{-1}\right)$. Inoculum for $E$. gracilis co-cultivation with both contaminants consisted of the cell suspension of algae $(10 \mathrm{~mL}), S$. cerevisiae $(5 \mathrm{~mL})$ and B. subtilis $(5 \mathrm{~mL})$. Every 24 hours, one flask (from each experimental setup) was taken off from the rotary shaker for analytical purposes. During flask cultivations E. gracilis was not exposed to light. All flask cultivations of E. gracilis were done in triplicate and the standard deviation of experimental data was calculated.

\section{Heterotrophic cultivation of $E$. gracilis in the stirred tank bioreactor under different conditions}

Batch cultivation of E. gracilis in the stirred tank bioreactor on both media (modified Hutner and complex medium) was done after sterilization (together medium and bioreactor) at $121^{\circ} \mathrm{C}$ for $20 \mathrm{~min}$. All cultivations were performed at $28{ }^{\circ} \mathrm{C}$ and a bioreactor working volume of $5 \mathrm{~L}$, respectively. For E. gracilis co-cultivation on modified Hutner medium the inoculum contained the cell suspension of E. gracilis $(300 \mathrm{~mL}), S$. cerevisiae $(150$ $\mathrm{mL})$ and $B$. subtilis $(150 \mathrm{~mL})$. Inoculum for separate $E$. gracilis co-cultivation with contaminants on complex medium contained cell suspension of algae $(400 \mathrm{~mL})$ and contaminant $(200 \mathrm{~mL})$. In these cultivations, dissolved oxygen tension was maintained at $30 \%$ of air saturation by changing the air flow and stirrer speed rate. To ensure heterotrophic growth, the bioreactor was wrapped in aluminum foil in order to avoid light penetration. The monitoring of bioprocess performance was done by taking broth samples during E. gracilis cultivations. All algae cultivations in the bioreactor were repeated and the standard deviation of experimental data was determined.

\section{Analytical procedures and bioprocess efficiency}

Cell number density of E. gracilis was determined by microscopic cell counting in a Thoma chamber. Due to high mobility of algae cells, deactivation was done by addition of $1 \% \mathrm{H}_{2} \mathrm{SO}_{4}$ solution. Cell number density of S. cerevisiae and B. subtilis was determined by standard microbiological methods (medium for maintenance; Petri dishes at $28^{\circ} \mathrm{C} ; 72 \mathrm{~h}$ for $S$. cerevisiae and $96 \mathrm{~h}$ for B. subtilis). Determination of biomass concentration was done gravimetrically. For this purpose, homogenized samples were centrifuged at $3629 \times \mathrm{g}$ (Sanyo, Harrier $18 / 80$ ) for 15 minutes and pellets were dried at $75^{\circ} \mathrm{C}$ to the constant mass. Supernatants were used for determination of glucose concentration with a Shimadzu CLASS-VP LC10AVP chromatograph with RI detector and Supelcogel
C-610H column. Phosphoric acid solution $\left(0.02 \mathrm{~mol} \mathrm{~L}^{-1}\right)$ in demineralized water (conductivity $<1 \mu \mathrm{S} \mathrm{cm}^{-1}$ ) was used as the mobile phase. Before chromatographic analysis the prepared supernatant solution was filtered through a nylon filter $(0.22 \mu \mathrm{m})$ and subsequently degassed in an ultrasonic bath for 20 minutes. Mobile phase flow rate was $0.5 \mathrm{~mL}$ $\mathrm{min}^{-1}$. Hydrogen peroxide concentration was determined by the CEFIC method (Anonymous 1, 2003).

Bioprocess efficiency parameters [biomass production $\left(X_{T}\right)$, conversion yield $\left(Y_{X S}\right)$ and productivity $\left.(P r)\right]$ were calculated by standard procedures (Ivušić and Šantek, 2015).

The production of biomass $\left(X_{T}\right)$ was calculated by following equation:

$$
X_{T}=X-X_{0}
$$

where $X$ and $X_{0}$ are biomass concentrations at the end and at the beginning of bioprocess, respectively.

Conversion yield of substrate into biomass $\left(Y_{X / S}\right)$ was estimated by following equation:

$$
Y_{X / S}=X_{T} /\left(S_{0}-S\right)
$$

where $S_{0}$ and $S$ are substrate concentrations at the beginning and the end of bioprocess, respectively.

Bioprocess productivity $(\mathrm{Pr})$ was determined by the following equation:

$$
\operatorname{Pr}=X_{T} /\left(t-t_{\theta}\right)
$$

where $t$ is the end and $t_{0}$ the start time of cultivation, respectively.

For calculation of $Y_{X / S}$ and $\operatorname{Pr}$ average values of $X_{T}$ (without standard deviation) were used. In this investigation, the standard deviation of substrate concentration was in the range of $\pm 0.1-0.6 \mathrm{~g} \mathrm{~L}^{-1}$ and the average values were used for $Y_{X S}$ calculation (data presented in Tables 1 - 3).

\section{RESULTS AND DISCUSSION}

The main purpose of this study was to examine the possibility to suppress the growth of different microorganisms during algae cultivation (or medium preparation) by using different chemical agents. $\mathrm{H}_{2} \mathrm{O}_{2}$ and antimycin were chosen as possible microorganism growth suppressors because of their properties. $\mathrm{H}_{2} \mathrm{O}_{2}$ was selected due to the fact that it can be very effective in relatively low concentrations because of its high oxidative properties. These properties are a consequence of $\mathrm{H}_{2} \mathrm{O}_{2}$ decomposition on water and nascent oxygen (Finnegan et al., 2010). Antimycin on the other hand was chosen based on its ability to inhibit microorganism (bacteria, molds and yeasts) growth even at low concentrations for a longer period of time (Franklin and Snow, 1975). In this research, 
E. gracilis was cultivated in different experimental conditions in order to define the effect of chemical agents on the growth of algae and representative contaminants $(S$. cerevisiae and B. subtilis). Yeast $S$. cerevisiae was selected as a representative of eukaryotic microorganisms (prefer acidic $\mathrm{pH}$ value $=4.5-5.0$ ) and $B$. subtilis as a representative of prokaryotic microorganisms (prefer a neutral $\mathrm{pH}$ value). During $E$. gracilis cultivation on modified Hutner medium, $\mathrm{H}_{2} \mathrm{O}_{2}$ concentration was also monitored and it was observed that its initial concentration was reduced by $25.48 \%$ in Erlenmeyer flasks and $32.56 \%$ in the stirred tank bioreactor after120 hours of bioprocess, respectively. Furthermore, similar tends of $\mathrm{H}_{2} \mathrm{O}_{2}$ concentrations were also observed during $E$. gracilis cultivation on complex medium where the initial $\mathrm{H}_{2} \mathrm{O}_{2}$ concentration was reduced by $29.23 \%$ in Erlenmeyer flasks and $35.64 \%$ in the stirred tank bioreactor after 120 hours of bioprocess, respectively.

\section{Heterotrophic cultivation of $\boldsymbol{E}$. gracilis on modified Hutner medium in different conditions}

At the beginning of this research, E. gracilis was cultivated in Erlenmeyer flasks on modified Hutner medium with different concentrations of $\mathrm{H}_{2} \mathrm{O}_{2}(1.5-15 \mathrm{mg}$ $\left.\mathrm{L}^{-1}\right)$ in order to define the impact of $\mathrm{H}_{2} \mathrm{O}_{2}$ concentration on the algae growth. The control cultivation of E. gracilis was done without $\mathrm{H}_{2} \mathrm{O}_{2}$ addition and, consequently, the highest bioprocess efficiency parameters were observed. These parameter values are in agreement with literature data (Šanteket al., 2009). As can be seen in Table 1, the increase of $\mathrm{H}_{2} \mathrm{O}_{2}$ concentration was related to the decrease of bioprocess efficiency parameters compared to the control cultivation of $E$. gracilis.

Considerable suppression of E. gracilis growth was detected during cultivation on modified Hutner medium with $\mathrm{H}_{2} \mathrm{O}_{2}$ concentration in the range of $1.5-7.5 \mathrm{mg} \mathrm{L}^{-1}$. This phenomenon is most obvious in the biomass production $\left(X_{T}\right)$ that was reduced by 42 - $48 \%$ compared to the control algae cultivation. Furthermore, parameters $Y_{X / S}$ and $\mathrm{Pr}$ were also reduced, but to a lower extent compared to the control cultivation. Further increase of $\mathrm{H}_{2} \mathrm{O}_{2}$ concentration was related to the almost complete suppression of algae growth, which was the most obvious for the cultivation on the modified Hutner medium with $15 \mathrm{mg} \mathrm{L}^{-1}$ of $_{2} \mathrm{O}_{2}$. In these experiments, bioprocess efficiency parameters were considerably reduced compared to the control cultivation. On the basis of these results it is clear that $\mathrm{H}_{2} \mathrm{O}_{2}$ has considerable impact on the E. gracilis growth. However, the growth of contaminants during $E$. gracilis cultivation was also suppressed and therefore for further research the $\mathrm{H}_{2} \mathrm{O}_{2}$ concentration of $5 \mathrm{mg} \mathrm{L}^{-1}$ was selected due to the fact that the highest bioprocess efficiency parameters were observed in this cultivation.

In our further research E. gracilis was cultivated on the modified Hutner medium with different antimycin
Table 1. Bioprocess efficiency parameters obtained during heterotrophic cultivation of $E$. gracilis in Erlenmeyer flasks on modified Hutner medium with $\mathrm{H}_{2} \mathrm{O}_{2}$ addition.

\begin{tabular}{cccc}
\hline $\begin{array}{c}\mathrm{H}_{2} \mathrm{O}_{2} \text { concentration } \\
\left(\mathrm{mg} \mathrm{L}^{-1}\right)\end{array}$ & $\begin{array}{c}X_{T} \\
\left(\mathrm{~g} \mathrm{~L}^{-1}\right)\end{array}$ & $\begin{array}{c}Y_{X / S} \\
\left(\mathrm{~g} \mathrm{~g}^{-1}\right)\end{array}$ & $\begin{array}{c}P r \\
\left(\mathrm{~g} \mathrm{~L}^{-1} \mathrm{~h}^{-1}\right)\end{array}$ \\
\hline 0 & $12.87 \pm 0.62$ & 0.660 & 0.107 \\
1.5 & $6.75 \pm 0.42$ & 0.373 & 0.056 \\
3 & $6.63 \pm 0.32$ & 0.368 & 0.055 \\
4.5 & $7.30 \pm 0.48$ & 0.405 & 0.061 \\
5 & $7.53 \pm 0.28$ & 0.560 & 0.063 \\
6 & $7.07 \pm 0.36$ & 0.413 & 0.059 \\
7.5 & $6.86 \pm 0.34$ & 0.387 & 0.057 \\
9 & $5.97 \pm 0.27$ & 0.364 & 0.050 \\
12 & $2.86 \pm 0.22$ & 0.062 & 0.024 \\
15 & $1.26 \pm 0.18$ & 0.031 & 0.011 \\
\hline
\end{tabular}

concentrations $\left(0.2-1.2 \mathrm{~g} \mathrm{~L}^{-1}\right)$ in order to define the impact of antimycin on the algae growth. The control cultivation of $E$. gracilis was done on the modified Hutner medium without antimycin addition. As can be seen in Table 2, a significantly higher impact on the E. gracilis growth was already observed at the lowest antimycin concentration $\left(0.2 \mathrm{gL}^{-1}\right)$ compared to the algae cultivation with $\mathrm{H}_{2} \mathrm{O}_{2}$ addition. At the lowest antimycin concentration biomass production was reduced by $73.4 \%$ compared to the control cultivation and a similar phenomenon was also detected for two other bioprocess efficiency parameters. The complete suppression of $E$. gracilis growth was detected at antimycin concentration higher than $0.3 \mathrm{~g} \mathrm{~L}^{-1}$ where negligible algae growth was observed. On the basis of these results it was decided that antimycin would not be used in our further research due to its significant inhibition of the $E$. gracilis respiratory chain. Furthermore, the application of antimycin on an industrial scale could enlarge antibiotic resistance in the environment (Franklin and Snow, 1975).

Table 2. Bioprocess efficiency parameters obtained during heterotrophic cultivation of E. gracilis in Erlenmeyer flask on modified Hutner medium with antimycin addition.

\begin{tabular}{cccc}
\hline $\begin{array}{c}\text { Antimycin } \\
\begin{array}{c}\text { concentration } \\
\left(\mathrm{g} \mathrm{L}^{-1}\right)\end{array}\end{array}$ & $\begin{array}{c}X_{T} \\
\left(\mathrm{~g} \mathrm{~L}^{-1}\right)\end{array}$ & $\begin{array}{c}Y_{X / S} \\
\left(\mathrm{~g} \mathrm{~g}^{-1}\right)\end{array}$ & $\begin{array}{c}P r \\
\left(\mathrm{~g} \mathrm{~L}^{-1} \mathrm{~h}^{-1}\right)\end{array}$ \\
\hline 0 & $12.32 \pm 0.58$ & 0.645 & 0.103 \\
0.2 & $3.28 \pm 0.27$ & 0.196 & 0.027 \\
0.3 & $2.71 \pm 0.21$ & 0.166 & 0.023 \\
0.35 & $0.80 \pm 0.12$ & 0.050 & 0.007 \\
0.5 & $0.14 \pm 0.04$ & 0.009 & 0.001 \\
0.6 & $0.06 \pm 0.01$ & 0.003 & 0.0005 \\
0.9 & 0 & 0 & 0 \\
1.2 & 0 & 0 & 0 \\
\hline
\end{tabular}


During E. gracilis co-cultivation with representative contaminants (S. cerevisiae and B. subtilis) on the modified Hutner medium their growth behavior was studied by $\mathrm{H}_{2} \mathrm{O}_{2}$ addition $\left(5 \mathrm{mg} \mathrm{L}^{-1}\right)$. In order to have a clear impact of $\mathrm{H}_{2} \mathrm{O}_{2}$ on $S$. cerevisiae and B. subtilis their separate cocultivations with $E$. gracilis were performed. As can be seen in Figure 1, the cell number of E. gracilis ( $\log \mathrm{N} 1)$ and dry biomass concentration were increased during cultivation as a consequence of glucose consumption. In this experiment, the cell number concentration of $S$. cerevisiae $(\log \mathrm{N} 2)$ was very slightly reduced as a consequence of $\mathrm{H}_{2} \mathrm{O}_{2}$ concentration decrease during the bioprocess because of its degradation. However, it has to be pointed out that dry biomass concentration represents the biomass of $E$. gracilis and $S$. cerevisiae due to the fact that it was not possible to separate these two microorganisms.

Therefore, it was not possible to determine the correct bioprocess efficiency parameters for E. gracilis co-cultivations with contaminants. On the basis of these results it is clear that the $\mathrm{H}_{2} \mathrm{O}_{2}$ concentration of $5 \mathrm{mg} \mathrm{L}^{-1}$ is sufficient to suppress the yeast growth during $E$. gracilis cultivation.

During cultivation of E. gracilis and B. subtilis on the modified Hutner medium (Figure 2) with $5 \mathrm{mg} \mathrm{L}^{-1}$ of $\mathrm{H}_{2} \mathrm{O}_{2}$ it was observed that the growth of $B$. subtilis cells was almost completely suppressed. Furthermore, the cell number concentration of $B$. subtilis was very slightly reduced due to the $\mathrm{H}_{2} \mathrm{O}_{2}$ activity although its concentration was also reduced during the bioprocess. The growth of E. gracilis was a consequence of glucose consumption and corresponds with the increase of dry biomass concentration. As mentioned above, the dry biomass concentration contains the dry biomass of E. gracilis and $B$. subtilis. Due to the fact that the bacterial cell number concentration was relatively low its portion in the total dry biomass concentration was also low and can be neglected.

In order to verify the results obtained from Erlenmeyer flasks the cultivation of E. gracilis in co-culture with $S$. cerevisiae and B. subtilis was performed in the stirred tank bioreactor on the modified Hutner medium with $5 \mathrm{mg}$ $\mathrm{L}^{-1}$ of $\mathrm{H}_{2} \mathrm{O}_{2}$. As can be seen in Figure 3, the cell numbers concentration of $S$. cerevisiae and B. subtilis were very slightly reduced during the whole heterotrophic cultivation of $E$. gracilis because of $\mathrm{H}_{2} \mathrm{O}_{2}$ activity. In the stirred tank bioreactor similar trends of cell number, dry biomass and glucose concentration were observed as during $E$. gracilis flask cultivation. On the basis of these results it is clear that the cultivation of E. gracilis in the stirred tank bioreactor confirms the results of algae cultivation in Erlenmeyer flasks.

\section{Heterotrophic cultivation of $E$. gracilis on complex medium in different conditions}

In this study, simple complex medium $\left(20 \mathrm{~g} \mathrm{~L}^{-1}\right.$ glucose and $60 \mathrm{~g} \mathrm{~L}^{-1} \mathrm{CSL}$ ) was used for E. gracilis cultivation in heterotrophic conditions in order to define its potential for industrial application as well as to define the capacity of $\mathrm{H}_{2} \mathrm{O}_{2}$ to prevent contaminant activities in these conditions. For $E$. gracilis cultivation on the complex medium the $\mathrm{H}_{2} \mathrm{O}_{2}$ concentration of $5 \mathrm{mg} \mathrm{L}^{-1}$ was selected due to the fact that this concentration was sufficient to prevent the growth of contaminants during algae cultivation on modified Hutner medium. The flask cultivation of $E$. gracilis on the complex medium was performed in different experimental conditions (Table 3; A). The control cultivation of $E$. gracilis was done without $\mathrm{H}_{2} \mathrm{O}_{2}$ and contaminants addition and the obtained bioprocess efficiency parameters were in the range of literature data (Šantek et al., 2009; Ivušić and Šantek, 2015).

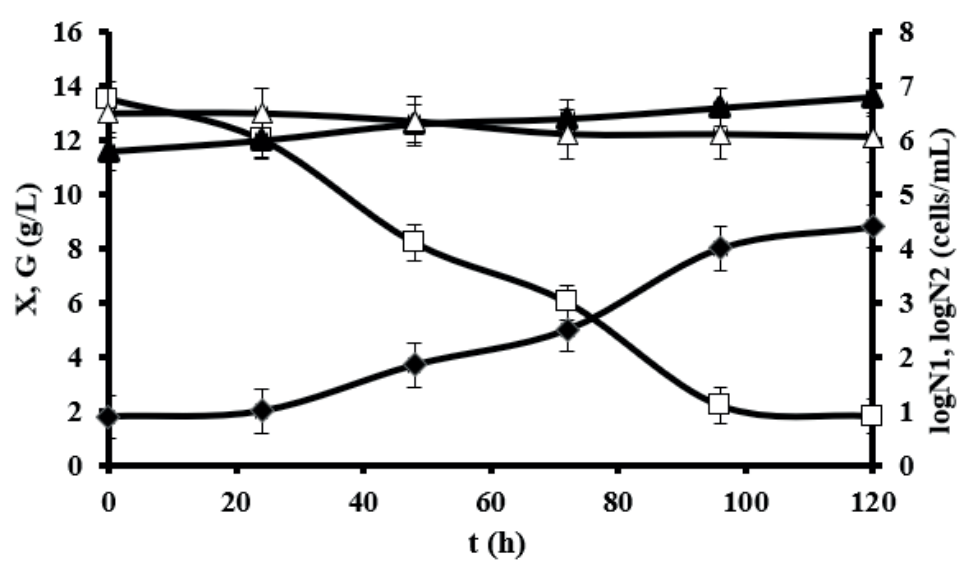

Figure 1. Changes of dry biomass $(\mathrm{X} ;)$ and glucose $(\mathrm{G} ; \square)$ concentration and cell number concentration of E. gracilis (log N1; $\mathbf{\Delta})$ and $S$. cerevisiae $(\log \mathrm{N} 2 ; \Delta)$ during cultivation on modified Hutner medium with $5 \mathrm{mg} \mathrm{L}^{-1} \mathrm{H}_{2} \mathrm{O}_{2}$ in Erlenmeyer flasks. 


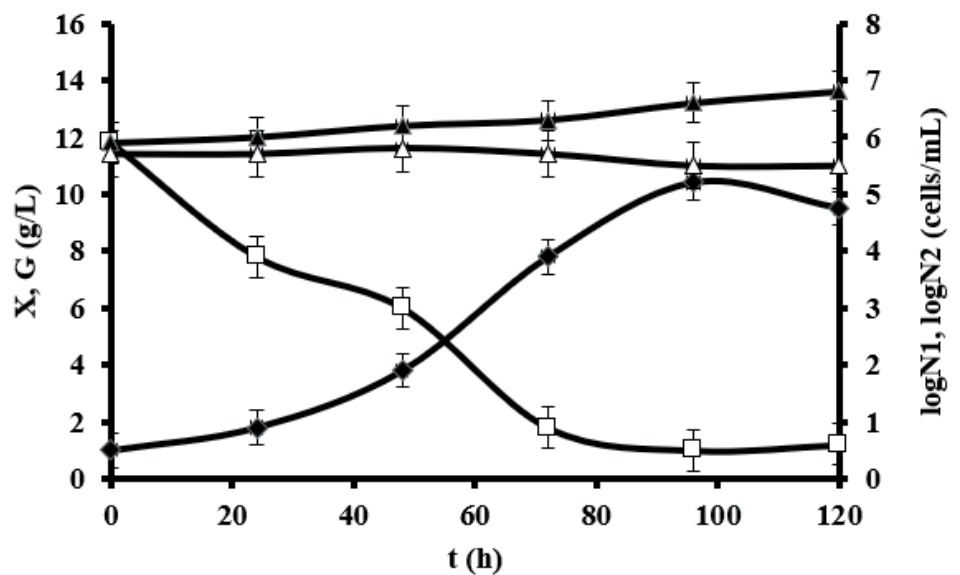

Figure 2. Changes of dry biomass $(\mathrm{X} ; \bullet)$ and glucose $(\mathrm{G} ; \square)$ concentration and cell number concentration of E. gracilis $(\log \mathrm{N} 1 ; \mathbf{\Delta})$ and $B$. subtilis $(\log \mathrm{N} 2 ; \Delta)$ during cultivation on modified Hutner medium with $5 \mathrm{mg} \mathrm{L}^{-1} \mathrm{H}_{2} \mathrm{O}_{2}$ in Erlenmeyer flasks.

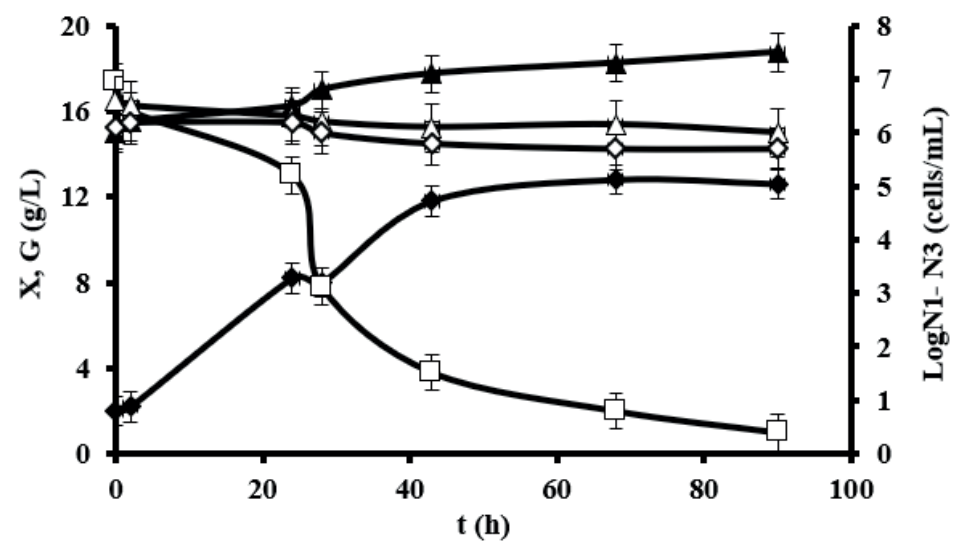

Figure 3: Changes of dry biomass $(\mathrm{X} ; \bullet)$ and glucose $(\mathrm{G} ; \square)$ concentration and cell number concentration of E. gracilis (log N1; $\mathbf{\Delta}), S$. cerevisiae $(\log \mathrm{N} 2 ; \Delta)$ and $B$. subtilis $(\log \mathrm{N} 3 ; \diamond)$ during cultivation on modified Hutner medium with $5 \mathrm{mg} \mathrm{L}^{-1} \mathrm{H}_{2} \mathrm{O}_{2}$ in the stirred tank bioreactor.

Table 3. Bioprocess efficiency parameters obtained during heterotrophic cultivation of E. gracilis in Erlenmeyer flask (A) and stirred tank bioreactor (B) on complex medium (CM) in different conditions.

\begin{tabular}{|c|c|c|c|}
\hline $\begin{array}{l}\text { Cultivation system: } \\
\text { A) Erlenmeyer flasks }\end{array}$ & $\begin{array}{l}X_{T} \\
\left(g^{-1} L^{-1}\right)\end{array}$ & $\begin{array}{l}Y_{X / S} \\
\left(g^{-1}\right)\end{array}$ & $\begin{array}{l}\boldsymbol{P r} \\
\left(\mathrm{g} \mathrm{L}^{-1} \mathrm{~h}^{-1}\right)\end{array}$ \\
\hline $\mathrm{CM}$ & $10.80 \pm 0.54$ & 0.600 & 0.090 \\
\hline $\mathrm{CM}+5 \mathrm{mg} \mathrm{L}^{-1} \mathrm{H}_{2} \mathrm{O}_{2}$ & $7.94 \pm 0.33$ & 0.490 & 0.066 \\
\hline $\mathrm{CM}+5 \mathrm{mg} \mathrm{L}^{-1} \mathrm{H}_{2} \mathrm{O}_{2}+S$. cerevisiae + B. subtilis & $8.01 \pm 0.39$ & 0.410 & 0.066 \\
\hline \multicolumn{4}{|l|}{ B) Stirred tank bioreactor } \\
\hline $\mathrm{CM}$ & $10.74 \pm 0.58$ & 0.594 & 0.086 \\
\hline $\mathrm{CM}+S$. cerevisiae $+5 \mathrm{mg} \mathrm{L}^{-1} \mathrm{H}_{2} \mathrm{O}_{2}$ & $7.40 \pm 0.39$ & 0.416 & 0.062 \\
\hline $\mathrm{CM}+$ B. subtilis $+5 \mathrm{mg} \mathrm{L}^{-1} \mathrm{H}_{2} \mathrm{O}_{2}$ & $6.95 \pm 0.31$ & 0.405 & 0.059 \\
\hline
\end{tabular}

In our further research, E. gracilis was cultivated on complex medium in the presence of $5 \mathrm{mgL}^{-1} \mathrm{H}_{2} \mathrm{O}_{2}$ and consequently a reduction of bioprocess efficiency parameters was observed. Bioprocess efficiency parameters were diminished compared to the control cultivation as follows: $X_{T}$ for $26.5 \%, Y_{X S}$ for $18.3 \%$ and $\operatorname{Pr}$ for $26.7 \%$.
However, this reduction of bioprocess efficiency parameters was lower compared to the algae cultivation on the modified Hutner medium. This phenomenon can be explained as a consequence of higher capacity of complex medium (considerably higher content of compounds that have higher potential to prevent oxidation than in the modified Hunter 
medium) to neutralize the nascent oxygen activity. During $E$. gracilis flask cultivation on complex medium in coculture with both contaminants (S. cerevisiae and B. subtilis) and $\mathrm{H}_{2} \mathrm{O}_{2}$ addition, similar values of bioprocess efficiency parameters were obtained as in previous experiments. It has to be pointed out that these values are only estimates due to the fact that it was not possible to separate algae and contaminants during dry biomass determination. As can be seen in Figure 4, the cell numbers of $S$. cerevisiae and $B$. subtilis were very slightly reduced, which clearly indicates that $\mathrm{H}_{2} \mathrm{O}_{2}$ can successfully supress the growth of both microorganisms. Similar growth suppression of both contaminants was also observed during E. gracilis cultivation on the modified Hutner medium.

In our further research, E. gracilis was cultivated in the stirred tank bioreactor in order to verify results obtained during algae flask cultivation on complex medium. As can be seen in Table 3 (B), control cultivation of E. gracilis was done in the stirred tank bioreactor without $\mathrm{H}_{2} \mathrm{O}_{2}$ addition. In these conditions, the range of bioprocess efficiency parameters was similar to the algae flasks cultivation on complex medium. On the basis of this result it is obvious that complex medium (consisting of $20 \mathrm{~g} \mathrm{~L}^{-1}$ glucose and $60 \mathrm{~g} \mathrm{~L}^{-1} \mathrm{CSL}$ ) can be successfully used for E. gracilis cultivation instead of chemically defined Hutner medium. In order to define the impact of $\mathrm{H}_{2} \mathrm{O}_{2}$ on the growth of contaminants, separate co-culture with E. gracilis were done in the stirred tank bioreactor on complex medium. As can be seen in Table 3 (B), the similar range of bioprocess efficiency parameters was observed in these cultivations as during algae flasks cultivations on complex medium. The E. gracilis co-culture with $B$. subtilis on complex medium was chosen (Figure 5) as an example of algae cultivation in the stirred tank bioreactor.

As can be seen in Figure 5, similar bioprocess behavior was observed as during E. gracilis flask cultivations on complex medium (Figure 4) and modified Hutner medium in the stirred tank bioreactor (Figure 3), respectively. On the basis of these results it is clear that E. gracilis flask cultivations on the complex medium are verified during algae cultivations in the stirred tank bioreactor.

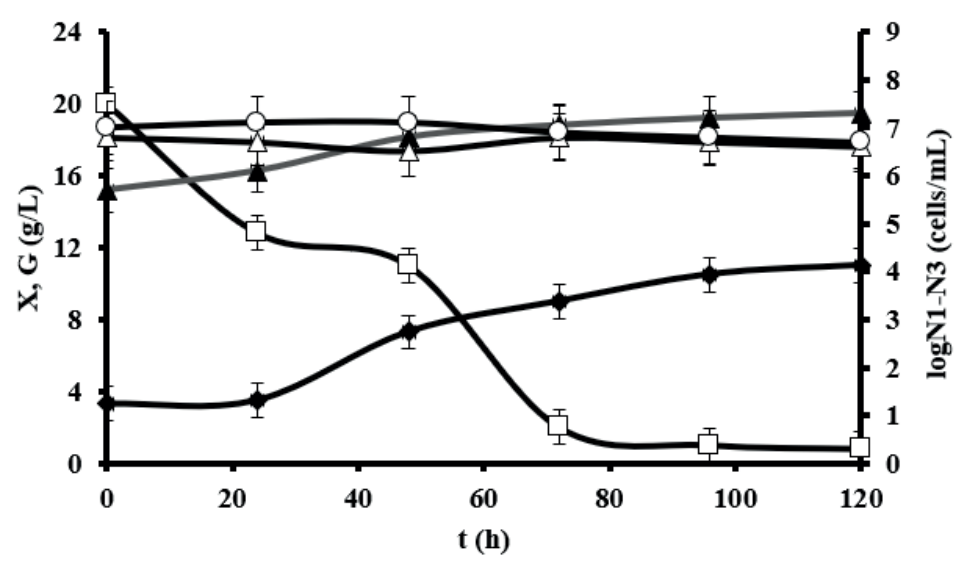

Figure 4. Changes of dry biomass $(\mathrm{X} ; \boldsymbol{)}$ ) and glucose $(\mathrm{G} ; \square)$ concentration and cell number concentration of E. gracilis (log N1; $\mathbf{\Delta})$, S. cerevisiae $(\log \mathrm{N} 2 ; \Delta)$ and $B$. subtilis $\left(\log \mathrm{N} 3 ; \circ\right.$ ) during cultivation on complex medium with $5 \mathrm{mg} \mathrm{L}^{-1} \mathrm{H}_{2} \mathrm{O}_{2}$ in Erlenmeyer flasks.

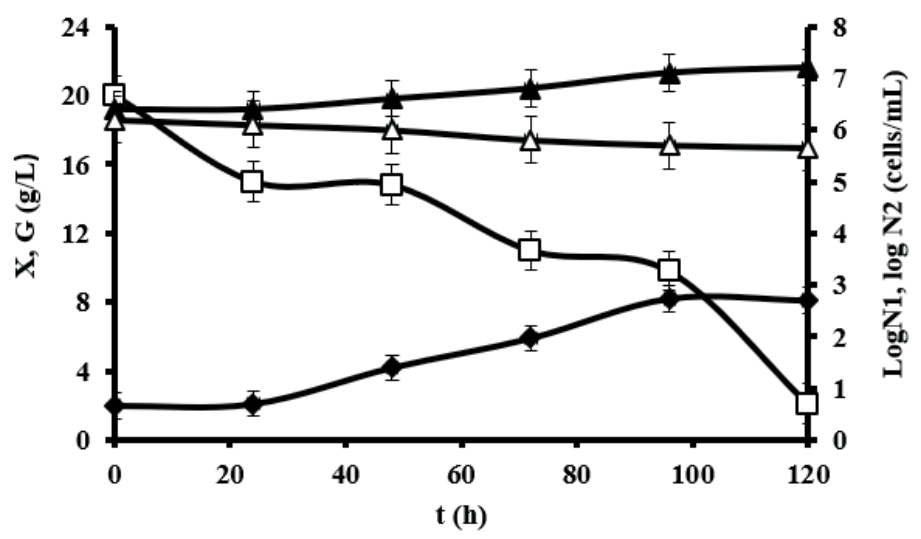

Figure 5. Changes of dry biomass $(\mathrm{X} ;)$ and glucose $(\mathrm{G} ; \square)$ concentration and cell number concentration of E. gracilis (log N1; $\mathbf{\Delta})$ and $B$. subtilis ( $\log \mathrm{N} 2 ; \Delta$ ) during cultivation on complex medium with $5 \mathrm{mg} \mathrm{L}^{-1} \mathrm{H}_{2} \mathrm{O}_{2}$ in the stirred tank bioreactor. 


\section{CONCLUSIONS}

On the basis of obtained results it can be concluded that complex medium (consisting of $20 \mathrm{~g} \mathrm{~L}^{-1}$ glucose and $60 \mathrm{~g} \mathrm{~L}^{-1} \mathrm{CSL}$ ) can be successfully used as a substitute for chemically defined Hutner medium. This observation is confirmed by the similar values of bioprocess efficiency parameters for E. gracilis cultivation on both media. Antimycin as a chemical agent significantly suppresses the growth of E. gracilis and contaminants already at relatively low concentrations (below $0.2 \mathrm{gL}^{-1}$ ). Therefore, it is not recommendable to use antimycin as a chemical suppressor of contaminants during E. gracilis cultivation. $\mathrm{H}_{2} \mathrm{O}_{2}$ as a chemical suppressor has lower impact on $E$. gracilis and contaminant growth than antimycin. At $\mathrm{H}_{2} \mathrm{O}_{2}$ concentrations up to $5 \mathrm{mg} \mathrm{L}^{-1}$, E. gracilis has the capability to grow, but the growth of representative contaminants was almost completely stopped. However, further increase of $\mathrm{H}_{2} \mathrm{O}_{2}$ concentration was related to the complete suppression of $E$. gracilis growth, especially for $\mathrm{H}_{2} \mathrm{O}_{2}$ concentration higher than $9 \mathrm{mg} \mathrm{L}^{-1}$. On the basis of these results it is obvious that $\mathrm{H}_{2} \mathrm{O}_{2}$ has great potential for application as a chemical suppressor of contaminants during E. gracilis cultivation (or medium preparation) on an industrial scale, but it is necessary to determine the optimal $\mathrm{H}_{2} \mathrm{O}_{2}$ concentration for particular bioprocess conditions.

\section{REFERENCES}

Almo, S.C. and Love, J.D., Better and faster: improvements and optimization for mammalian recombinant protein production. Current Opinion in Structural Biology, 26, 39-43 (2014).

Anonymous 1, CEFIC Peroxygens $\mathrm{H}_{2} \mathrm{O}_{2}$ AM-7157, Determination of hydrogen peroxide concentration, Titrimetric method (www.cefic.org/Documents/Other/CEFIC-H2O2-7157.pdf) (2003).

Farrell, A., McLoughin. N., Milne, J.J., Marison, I.W. and Bones, J., Application of multi-omics techniques for bioprocess design and optimization in Chinese hamster ovary cells. Journal of Proteome Research, 13, 3144-3159 (2014).

Finnegan, M., Linley, E., Denyer, S.P., McDonnell, G., Simons, C. and Maillard, J.Y., Mode of action of hydrogen peroxide and other oxidizing agents: differences between liquid and gas forms. ournal of Antimicrobial and Chemotherapy, 65, 2108-2115 (2010).

Franklin, T.J. and Snow, G.A., Biochemistry of antimicrobial action. Chapman and Hall Ltd, London, p. 139-157 (1975).

Hutner, S.H., Zahalsky, A.C., Aronson, S.A., Baker, H.and Frank, O., Culture media for Euglena gracilis. In: D M Prescott (ed.), Methods in Cell Physiology (vol. II; p. 217-228), Academic Press, New York London (1966).

Ivušić, F.and Šantek, B., Optimization of complex medium composition for heterotrophic cultivation of Euglena gracilis and paramylon production. Bioprocess and BiosystemEngineering, 38, 1103-1112 (2015).

Kennedy, M. and Krouse, D., Strategies for improving fermentation medium performance: a review. Journal of IndustrailMicrobiology and Biotechnology, 23, 456-475 (1999).

Koizumi, N., Sakagami, H., Utsumi, A., Fujinaga, S., Takeda, M., Asano, K., Sugewara, I., Ichikawa, S. and Kondo, H., AntiHIV (human immunodeficiency virus) activity of sulfated paramylon. Antiviral Research, 21, 1-14 (1993).

Koller, M., Hesse, P., Salerno, A., Reiterer, A. and Braunegg, G. A viable antibiotic strategy against microbial contamination in biotechnological production of polyhydroxyalkanoates from surplus whey. Biomass and Bioenergy, 35, 748-753 (2011).

Li, J., Baral, N.R. and Ha, A.K.J., Acetone-butanol-ethanol fermentation of corn stover by Clostridiumspecies: present status and future perspectives. World Journal of Microbiology and Biotechnology, 30, 1145-1157 (2014).

Manivasagan, P., Venkatesan, J., Kang, K.H., Sivakumar, K., Park, S.J. and Kim, S.K., Production of $\alpha$-amylase for the biosynthesis of gold nanoparticles using Streptomyces sp. MBRC-82. International Journal of Biology and Macromolecules, 72, 71-78 (2015).

Murakami, T., Ogawa, H., Hayashi, M. and Yoshizumi, H., Effect of Euglena cells on blood pressure, cerebral peripheral vascular changes and life-span in strokeprone spontaneously hypertensive rats. Journal of Japan Sociaty of Nutritionand Food Sciences, 41, 115-125 (1998).

Ogbona, J.C., Tomiyama, S. and Tanaka, H., Heterotrophic cultivation of Euglenagracilis $\mathrm{Z}$ for efficient production of $\alpha$-tocopherol. Journal of Applied Phycology, 10, 67-74 (1998).

Oliveira, R. C., Gomez, J. G., Torres, B. B., Bueno Netto, C. L. and Silva, L. F. D. A suitable procedure to choose antimicrobials as controlling agents in fermentations performed by bacteria. Brazilian Journal of Microbiology, 31, 87-89 (2000).

Osafune, T., Sumida, S., Ehara, T., Ueno, N., Hase, E. and Schiff, J.A., Lipid (wax) and paramylon as sources of carbon and energy for the early development of proplastids in dark-grown Euglena gracilis cells transferred to an inorganic medium. Journal of Electron Microscopy, 39, 372-381 (1990).

Šantek, B., Felski, M., Friehs, K., Lotz, M. and Flaschel, E., Production of paramylon, a $\beta$-1,3-glucan, by heterotrophic cultivation of Euglena gracilis on potato liquor. Engineering in Life Sciences, 10, 165-170 (2010).

Šantek, B., Felski, M., Friehs, K., Lotz, M. and Flaschel, E,. Production of paramylon, a $\beta$-1,3-glucan, by heterotrophic cultivation of Euglena gracilis on a synthetic medium. Engineering in Life Sciences, 9, 23-28 (2009).

Šantek, B., Friehs, K., Lotz, M. and Flaschel, E., Production of paramylon, a $\beta$-1,3-glucan, by heterotrophic growth of Euglena gracilis on potato liquor in fed-batch and repeated batch mode of ultivation. Engineering in Life Sciences, 12, 89-94 (2012).

Wang, W., Han, F., Li, Y., Wu, Y., Wang, J., Pan, R. and Shen, G., Medium screening and optimization for photoautotrophic culture of Chlorella pyrenoidosa with high lipid productivity indoors and outdoors. Bioresource Technology, 170, 395-403 (2014).

Watanabe, T., Shimada, R., Matsuyama, A., Yuasa, M., Sawamura, H., Yoshida, E. and Suzuki, K., Antitumor activity of the $\beta$-glucan paramylon from Euglena against preneoplastic colonic aberrant crypt foci in mice. Food \&Function, 4, 16851690 (2013). 